\title{
THE FORMATION OF THE RISK CONTROLLING SYSTEM IN THE ENTERPRISE
}

\author{
Myroslava D. Bedrinets ${ }^{1}$ \\ Oksana A. Lisnichuk ${ }^{2}$ \\ Yuliia V. Ananieva ${ }^{3}$
}

\begin{abstract}
Management of sustainable development of enterprises of any formation requires deploying risk management processes. The relevance of risk management is not in doubt, but the

introduction of risk management methods is quite problematic if the processes of information base formation, analysis, planning and control of risks are not coordinated. At the enterprise, this function is provided by the riskcontrolling system. The introduction of a financial risk management system based on the construction of financial risk controlling is an innovative step towards the introduction of a fundamentally new level of financial management at enterprises. In the paper the basic problems of risk management at the Ukrainian enterprises are analyzed,
\end{abstract} methodical approaches to the formation of the risk-controlling system at the enterprise are considered, recommendations on its introduction are formulated.

Keywords: balanced scorecard, risk management, Ukrainian enterprises, planning, monitoring

\section{Introduction}

In a market economy, any enterprise inevitably faces situations that carry a risk, that is, unforeseen events, to which it is necessary to respond adequately in order not to suffer losses or not to get another undesirable result (Blank, 2015). This or that manifestation of uncertainty may: delay the planned events; change their content or

University of the State Fiscal Service of Ukraine, Universytetska Street, 31., Irpin, 08201, Ukraine. E- ${ }^{1}$ mail: myr.bedriners@nuos.pro

${ }^{2}$ University of the State Fiscal Service of Ukraine, Universytetska Street, 31., Irpin, 08201, Ukraine

${ }^{3}$ University of the State Fiscal Service of Ukraine, Universytetska Street, 31., Irpin, 08201, Ukraine 
quantitative result; cause undesirable event scenarios, both predictable and unpredictable. As a result, the chosen goal will not be achieved. Classification of risks in enterprise management systems is a difficult task because of such features (Podolchak, 2003): the presence of a large number of risks, which the company constantly faces when making both current and long-term decisions. As noted by V.V. Cherkasov (1999), at the present stage there are more than 40 different criteria and more than 220 risk types; the impossibility of clearly delineating risks, as they are closely related to each other; the diversity of risks, some of which are manifested in the industry-specific activities of any enterprise, others are inherent only in the activities of individual enterprises (e.g. mechanical engineering or aircraft construction); the speed of world countries economic and political development, giving rise to new kinds and types of risks; differences in risks dynamics and intensity; the dynamics of internal social and economic development of enterprises (Allalyev, 2019).

Any risk classification is not universal, as it is difficult to develop a universal risk classification because of
974

the above features. As a rule, classification is carried out in accordance with the set task or objective. Financial risk plays a significant role in the diversity of various risks affecting the operations of a production enterprise. Financial risk arising in the course of formation, distribution, redistribution and use of capital, income, funds, reserves and other monetary sources of the enterprise, is more susceptible to the influence of the external environment of the enterprise, which in modern Ukrainian conditions remains unpredictable and hostile (Vitlinsky, 2003; Bliznets et al. 2018).

In addition, production enterprises cannot use many of the financial risk management tools that are successfully used in other areas of entrepreneurship based on the use of high-risk situations, such as stock market transactions. Production enterprises are mostly forced to be more conservative, as unlike operators of foreign exchange (stock) markets or trade enterprises, they are limited by the scope of technologies and equipment used, types of raw materials and the sphere of choice of activities. Risk management should be carried out on the basis of an integrated approach, the main purpose of which is 
to integrate the management process into the operational and strategic activities of the enterprise (Gordadze et al., 2018; Kuznetsov et al., 2018).

The management system concept means a set of interrelated elements, a method of implementation of control technology, which involves the impact on the object in order to change its state and process characteristics (Pickford, 2004). The financial risk management system is a set of elements of risk management that allow ensuring a positive financial result in the presence of uncertainty in the conditions of financial and economic activity; predict the occurrence of a risk event and take measures to eliminate or reduce its negative consequences. When considering any organization management system, it is necessary to take into account the influence of many variables that are elements of the internal and external environment, ranging from legislation to the level of information technology development. The key element of the management system is the correct definition of the mission and setting of management objectives (Blank, 2004).

\section{Research Methodology}

The subject of the research is a set of theoretical, methodological and practical issues of forming a risk management system at an enterprise and the features of their analysis. The object of the research is the activity of the enterprise on the formation of the risk management system. The theoretical and methodological basis of the study was the scientific work of domestic and foreign authors in the field of risk management, enterprise risk assessment.

The study of the topic was carried out on the basis of general scientific research methods - a systematic approach, analysis and synthesis, methods of logical modeling. The authors have developed a methodological basis for the formation of a risk management system at an enterprise, which can be used to form a risk management system that contributes to an increase in the efficiency of their functioning. The theoretical value of the work in the systematization of methods for assessing and analyzing risks, considering their place in the system (Kudabaeva et al., 2015; Kudabayeva et al., 2018).

\section{Results and Discussion}


Specifics of the Interrelation of Riskcontrolling and Risk-management

The company objectives are determined on the basis of the mission. It is the goals that constitute the benchmark against which all the organization processes should be directed. Targeted management is a central part of the performance management process as it allows the activities of the company to be directed towards achieving global goals and then assess the degree of achievement of those goals. Implementation of goals is usually achieved through various strategies, the effectiveness of which depends directly on the effective actions of the company management. The strategy defines the direction of business development and movement methods in the direction chosen. The development of strategic thinking and strategic approaches to management has led to a change in the concepts of controlling; they contributed to the development of its strategic aspect, which is aimed at the formation of opportunities and development of strategies for adaptation and adaptation of the enterprise to changes occurring in the external environment, based on the construction of strategic planning and coordination (Reta et al., 2018). The
976

ability to identify risks in a timely manner and minimize them is an important task of effective enterprise management (Galiyeva, 2009). Regardless of the causes of risk occurrence, it is natural that the economic entity wishes to reduce possible losses associated with the implementation of this risk. This is accomplished by making management decisions whereby risk control (or risk management) occurs.

In the most general form, the objectives of risk management are: preserving the enterprise resources; obtaining the largest profit as a result of the decision made at the set profit to risk ratio. The experience of corporate risk management of foreign and some large Ukrainian enterprises allows us to characterize risk management as a multistage process that includes: determining the conditions in which the company operates; risk identification; risk analysis and determination of risk level; selection of management methods and application of risk management techniques; monitoring of results and improvement of the risk management system (Bedrinets and Surzhenko, 2016). Risk management in our country as a separate theoretical and practical 
direction emerged in the 1990s. It was at that time that industrial enterprises realized the need to implement a comprehensive risk management system. It turned out that, despite the rapid development of theoretical and methodological base, companies do not have solutions suitable for implementation in daily activities, and consultants who develop and actively use risk methods, are not always able to adapt them to customer company needs.

Practical studies of the results of the implementation of risk management in a number of domestic companies over the past decade have shown its relatively low efficiency, the main reason for which was the lack of integration into the financial management system of the enterprise. Depending on the degree of practical application of risk management at different enterprises, they can be subdivided into three groups (Keil, 2008). The first group includes those enterprises in which risk management is identified with only one measure - insurance when all the main risks are transferred to an insurance company (Klapkiv, 2002). The second group covers the enterprises with the so-called fragmented risk management when in separate structural subdivisions the employees responsible for analysis and minimization of the most essential risks are appointed, and the coordination function is performed by someone from among top-managers (most often a chief financial officer).

The third group includes companies that use a qualitatively more advanced approach to risk management - the introduction of risk management throughout the enterprise. In this case, in accordance with the scope of the organization activities, a special risk management unit may be created, which reports directly to the company management (mainly concerns large enterprises), or the risk manager position within a financial unit is introduced. As practice shows, the lack of competent risk management often leads to negative consequences for the enterprise such as: reduced financial stability; losses; deterioration in business reputation; a decrease in the exchange value of share; a tendency to negative financial processes. Moreover, the analysis of the results of financial management in domestic enterprises in the context of the financial and economic crisis has shown the lack of balance and often unjustified risky financial policy of many companies, which had an impact on their 
financial performance. Most modern economic conditions are as follows: the increased competition requires enterprises to take on new risks; increasing requirements for risk disclosure inherent in the organization to owners, creditors, and regulatory authorities; increasing vulnerability of businesses to international financial crises and economic downturns caused by the globalization of the world economy. Therefore, the problem of effective risk management in the enterprise becomes especially urgent. Risk management becomes one of the most important elements of financial management (Kerimov et al., 2018a; Kerimov et al., 2018b).

The practice has shown that the introduction of risk management methods at an enterprise is rather problematic if the processes of formation of the information base, analysis, planning and control of risks are not coordinated. Coordination of internal management processes, analysis of factors of the external and internal environment of the enterprise is carried out by controlling. Taking into account the analysis of the main scientific works on the research subject, the riskcontrolling will be understood as a
978

control and information subsystem of controlling aimed at achieving the goals of risk management and ensuring the coordination of its functions in all business processes (Karmansky and Falko, 2006; Kerimov et al., 2018c).

Ideally, controlling finds common ground between the functional components of management, creating a unified management system, and adapts the system to new requirements when the environment changes. Moreover, for the system to function effectively, controllers should provide an independent assessment system of management actions. This makes managers react more accurately to changes and also shows the ratio of efficiency of various business units (Bedrinets and Denega, 2018). Thus, risk-controlling can be defined as a controlling subsystem designed to: coordinate risk planning and control; provide risk management and general management information to support leadership in making financial decisions.

The main purpose of riskcontrolling is to provide information support to management for the integrated and objective management of risk management processes at the enterprise. At the stages of plotting and 
implementation, the risk-controlling system should solve the following tasks: selection of indicators - a rather responsible and ambiguous process. This is particularly evident when nonfinancial indicators are defined. Insignificant factors should be excluded from consideration; assessment of targets for key indicators. Successful development of the enterprise largely depends on the right development trajectory chosen. Too high values can lead to inefficient use of resources. Too low leads to underutilization of available capacity. In addition, uncertainty and ambiguity must be taken into account; establishing links between the indicators. Availability of clear interrelations between the indicators, determined in quantitative terms, allows to determine the reasons for deviations of indicators from standard values and to predict the results of the company activity; regular updating of the indicator system, which should be kept up to date. This is especially true for the assessment of normative values - this process requires
979

significant time, analytical costs of top management; assessment of possible development options by means of simulation of the system in order to prevent high losses, as well as to respond flexibly to market changes; specification of strategic goals and objectives in case of changes in external and internal conditions of business activities (Kerimov et al., 2017).

According to the tasks performed, risk-controlling performs the following functions at the enterprise: information and analytical; controlling; methodical; coordinating; and advisory (Vaganova, 2010). The most important is considered to be the information and analytical and methodical support of the risk management system to achieve risk management strategic and operational goals of an enterprise. The scheme of the interrelation of risk management and risk-controlling at the enterprise can be presented as follows (Figure 1). Thus, risk-controlling and risk-management processes complement each other. 


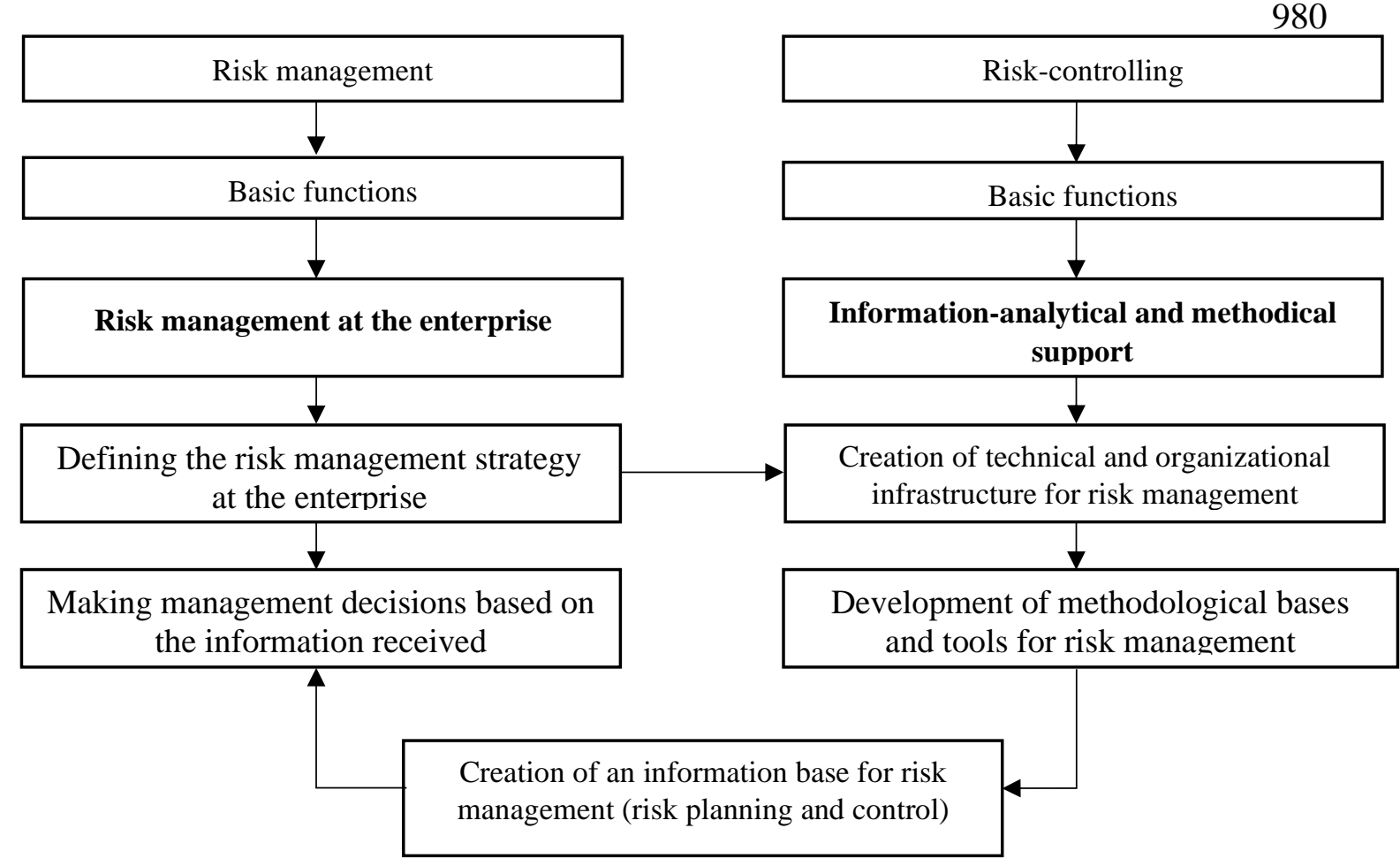

Figure 1. Scheme of interaction between risk management and risk-controlling

The Process of Formation of the Riskcontrolling System

Stages of formation of the riskcontrolling system. The use of riskcontrolling at Ukrainian enterprises could increase the efficiency of risk management. Meanwhile, riskcontrolling is very rarely used by domestic enterprises. The tool of controlling, which allows managing the company strategic goals and monitoring efficiency of business processes and the enterprise as a whole, is a balanced scorecard system (Taran, 2004). Strategy to be presented in the form of a map, on which the strategic objectives is connected by cause-and-effect ties. The strategic map is a checklist of strategic components and their interactions (Figure 2). 


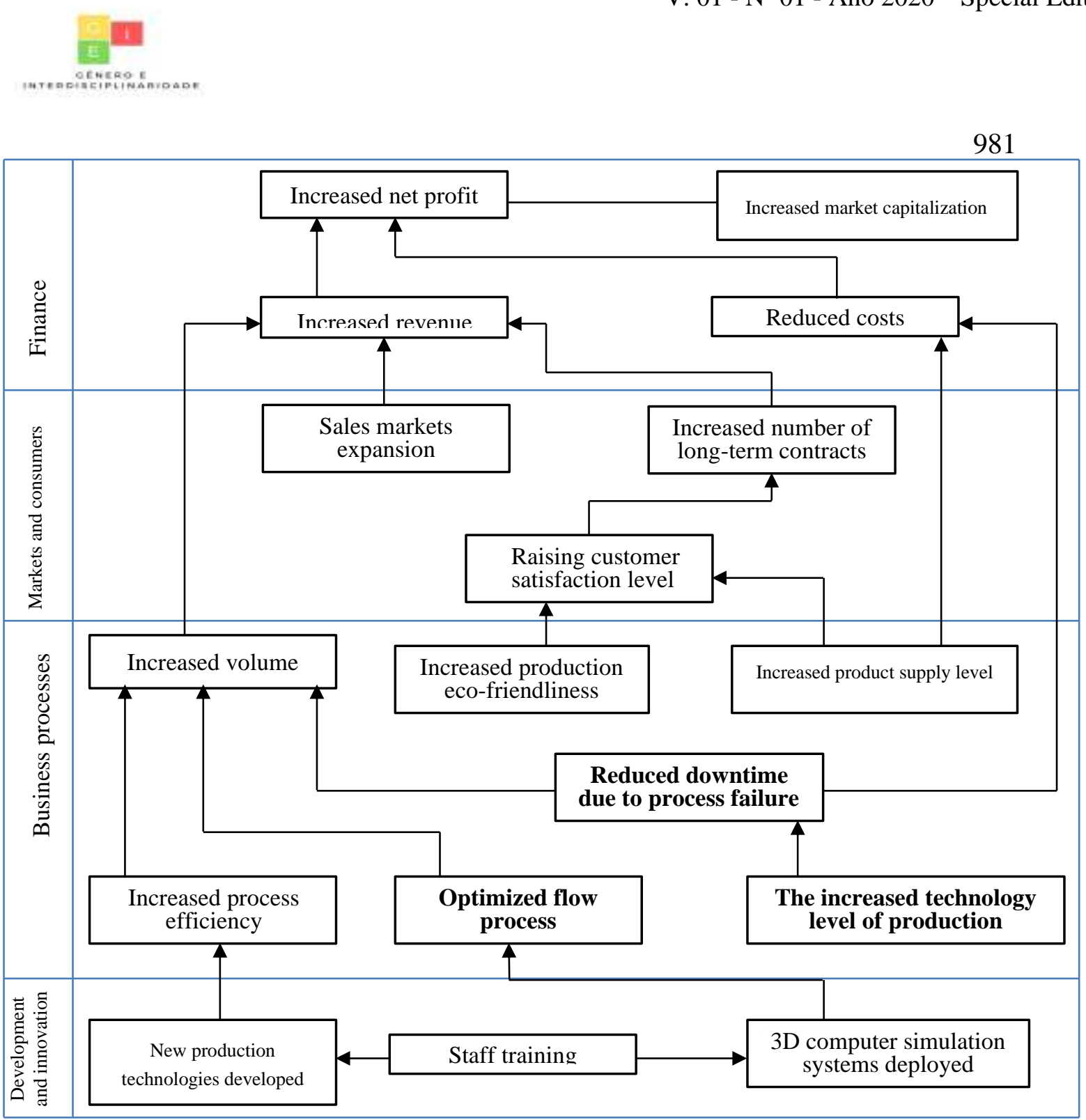

Figure 2. Cause-and-effect relationships between enterprise strategy elements

The absence of key elements leads to the failure of the strategy. Identifying dependencies between business process indicators enables a deeper understanding of development trends, assessing emerging risks when certain scenarios are implemented. In addition, there is an external factor that affects enterprises, such as market prices for goods, tax rates, and export duties. In the context of financial goals, the primary goal of any company represented in the stock market is to increase market capitalization, which depends on the absolute rate of return, namely: gross revenue (GR), net sales (NS), gross profit, operating profit (OP), earnings before tax (EBT), and net operating profit after taxes (NOPAT). Net profit of the enterprise depends on 
982

the volume of production costs and sales volumes. Achievement of the goals of revenue increase is provided by expansion of sales markets, increase of long-term contracts and product output growth (Folmut, 2007).

Moving on to business processes, it is worth noting the most important strategic goals, such as expanding production, optimizing the flow process, improving eco-friendliness of production and efficient transportation. Development and innovations of the enterprise depend on the development of new production technologies, the introduction of modern 3D-modeling systems and training of personnel in new technologies. The use of the mathematical apparatus of fuzzy logic and the rules obtained thereby allows us to maintain the clarity inherent in the classical balanced scorecard system. Specifying the exact meaning is complex and only makes sense as a reference point. Owing to those functional influence dependences of all variables on each other are unknown, and plotting of exact mathematical model is impossible; it makes sense to use a fuzzy logic conclusion which imitates mental activity of a decisionmaker. There is always an interval of permissible variation of the variable due to the impossibility to take into account and foresee the influence of all factors, for example, macroeconomic risks (Kim, 2005; Lapidus et al., 2018a).

In this regard, the transition to linguistic variables allows us to move away from absolute values and thereby unify the established rules. Let us consider the stages of risk-controlling system formation at the enterprise. The development of a risk controlling system should begin with the definition of strategic goals and setting risk management objectives. The tasks and objectives of risk management may vary depending on the company specifics but should be clearly defined before the system plotting process begins. The next step in plotting a risk controlling system is to adjust the company mission, based on which owners and leadership determine the activity strategic goals.

While setting goals, owners set the level of risk they are willing to assume to achieve the desired goals, i.e. determine the company risk propensity. The company risk propensity can be qualitatively formulated at the strategic management level: high risk; medium risk; low risk. Quantitative assessment (through some set of indicators), i.e. at 
the operational level, is used too. The company risk-based propensity, defined qualitatively on a strategic level, should be rendered into target quantitative risk level indicators. After the mission and the objectives of the organization are determined, the risk controlling system is positioned within the company taking account of the risk factor. At the same time, it should be decided which organizational form of risk management is most suitable for the company and who will use the system.

Many scientists say that the risk management system should penetrate the company completely. It may involve employees of various ranks and from different departments of the company. At the same time, it must be borne in mind that the establishment and functioning of independent risk management services
983 are linked to the use of substantial labor and financial resources. Therefore, a separate risk control unit should only be created in large companies. It is advisable to introduce an authorized risk manager with small analytical support staff in medium and small organizations. Direct risk management functions can be transferred to the financial service departments, and risk-controlling functions can be successfully performed by analysts of planning and economic departments, management accounting services and internal audit of enterprises. The next stage in the formation of the risk-controlling system is the development of the risk-controlling procedure. The risk-controlling procedure should include the following steps (Figure 3). 


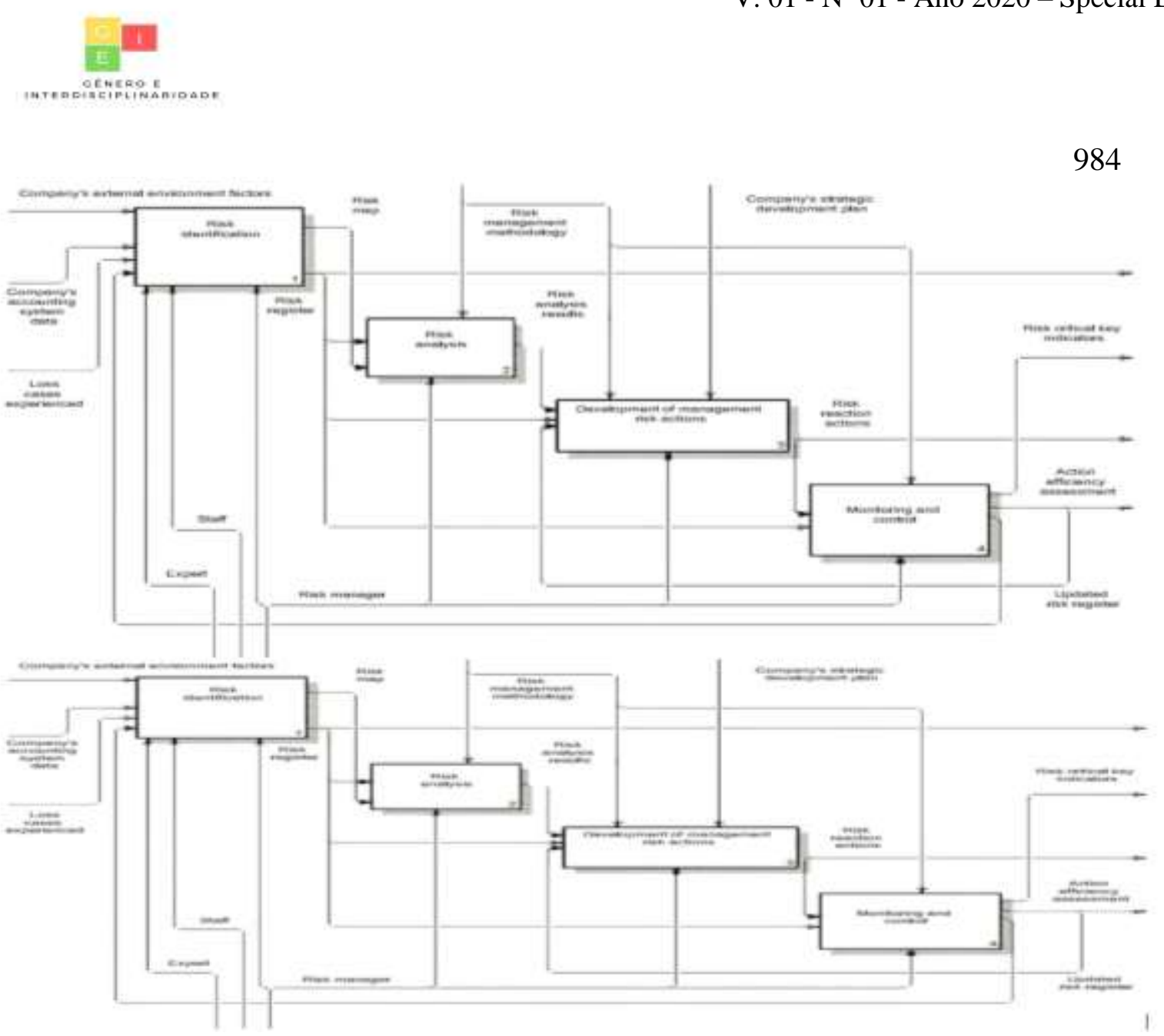

Figure 3. Risk-controlling procedure at an enterprise (developed by the author)

Let us consider the risk identification stage. An expert forms a risk event register. This stage begins with the completion of risk event data: a list of risk events is drawn up, data on risk event categories are filled in; lists of persons responsible for risk, lists of risk event causes, a list of risk response measures and a list of key risk indicators are to be drawn up. An expert fills in the data on categories and lists of responsible persons. In addition, an expert analyzes the information available at the enterprise on risk events that have already taken place and enters this information into the database. Data entry at the stage of risk identification is accompanied by meetings with the company management and personnel. For the purposes of visual analysis and to understand risk hierarchy, the expert links risk events and creates a risk map. Having identified the risks, the expert produces a report that is to be submitted to the management and shareholders of the company as part of an integrated risk management report. Let us turn to the risk analysis stage. The risk manager 
conducts a risk analysis after the formation of the risk register. Risk analysis includes two large groups of methods - qualitative and quantitative for risk analysis. The results of these analytical subgroups complement one another and the qualitative analysis normally precedes the quantitative.

As a result of the quantitative analysis, the risk assessment will be carried out, i.e. determination of the quantitative value of individual risks to provide the basis for appropriate management decisions. The main risk assessment parameters are the likelihood of risk occurrence and the amount of possible damage. Using the results of the analysis, the risk manager formulates recommendations on developing risk response measures. The risk manager, after carrying out risk modeling and analysis, prepares a survey report as part of a comprehensive risk management report. At the stage of development of risk management measures, the risk manager, using the recommendations received at the risk analysis stage, develops risk response measures, assigns responsible persons and points out key risk indicators. The risk manager separately forms risk prevention measures, measures to mitigate the impact of these risks and respond to the risks occurred. The risk manager produces a risk response measures report. Consider the monitoring and control stage. The risk manager enters in the monitoring and control module key risk indicators and risk response measures. Key risk indicators are monitored according to the schedule (Lapidus et al., 2018b).

The role of the risk manager in the risk-controlling system. The risk manager shall, in the event of deviation from the standard values: form a list of critical key indicators; assess the effectiveness of risk response measures; look through these events. It should be noted that the monitoring process should be continuously conducted by the company. This is the mechanism by which the following is implemented: continuous monitoring of controlled indicators; determining values of deviations between actual and planned results; identification of causes of these deviations. After the deviations have been identified, it is time to analyze their causes. However, it cannot and should not be continuous, because the analysis process can be quite difficult and the cost is not always paid off. Therefore, the nature of the deviation must be identified 
first: permanent or one time. In the latter case, it is not advisable to carry out the analysis if the difference does not exceed a certain threshold value. Only important deviations are analyzed whose criticality criteria are independently determined by each company.

Based on the monitoring results, the risk management system effectiveness in achieving the fixed goals is evaluated. The risk manager produces a comprehensive report, including: risk identification, analysis, and assessment results; risk response measured developed; results of monitoring and control over the previous period (quarter, year). It should be noted that in an increasing uncertainty, the complexity and speed of changes in both the company external environment and internal processes, as well as their limited predictability, determine the need for strategic and tactical management decisions. In this connection, it is expedient to use such financial management instruments that would allow potential business and external environment risks to be traced in interrelation with the company strategic objectives. Consequently, accounting for
986

risk factors is only effective when strategic management finds continuation in the company operational risk management (Nait, 2003). An early warning and response system must be implemented at the company, signaling to risk management and leadership the potential risks from both the external and internal environment that threaten the business entity. This means that it is advisable to create an enterprise-wide risk-controlling system that will contain elements of both strategic and operational controlling. Strategic riskcontrolling should be aimed at predicting and preventing possible crisis situations. Operational risk controlling involves preparing rapid response decisions to the following factors: negative changes in the external and internal environment; identifying violations of performance standards formulated in the process of strategic risk-controlling. Preparing information for making corrective decisions in a particular situation will be involved therein. Overall, the risk-controlling system functioning scheme in the company is presented in Figure 4. 


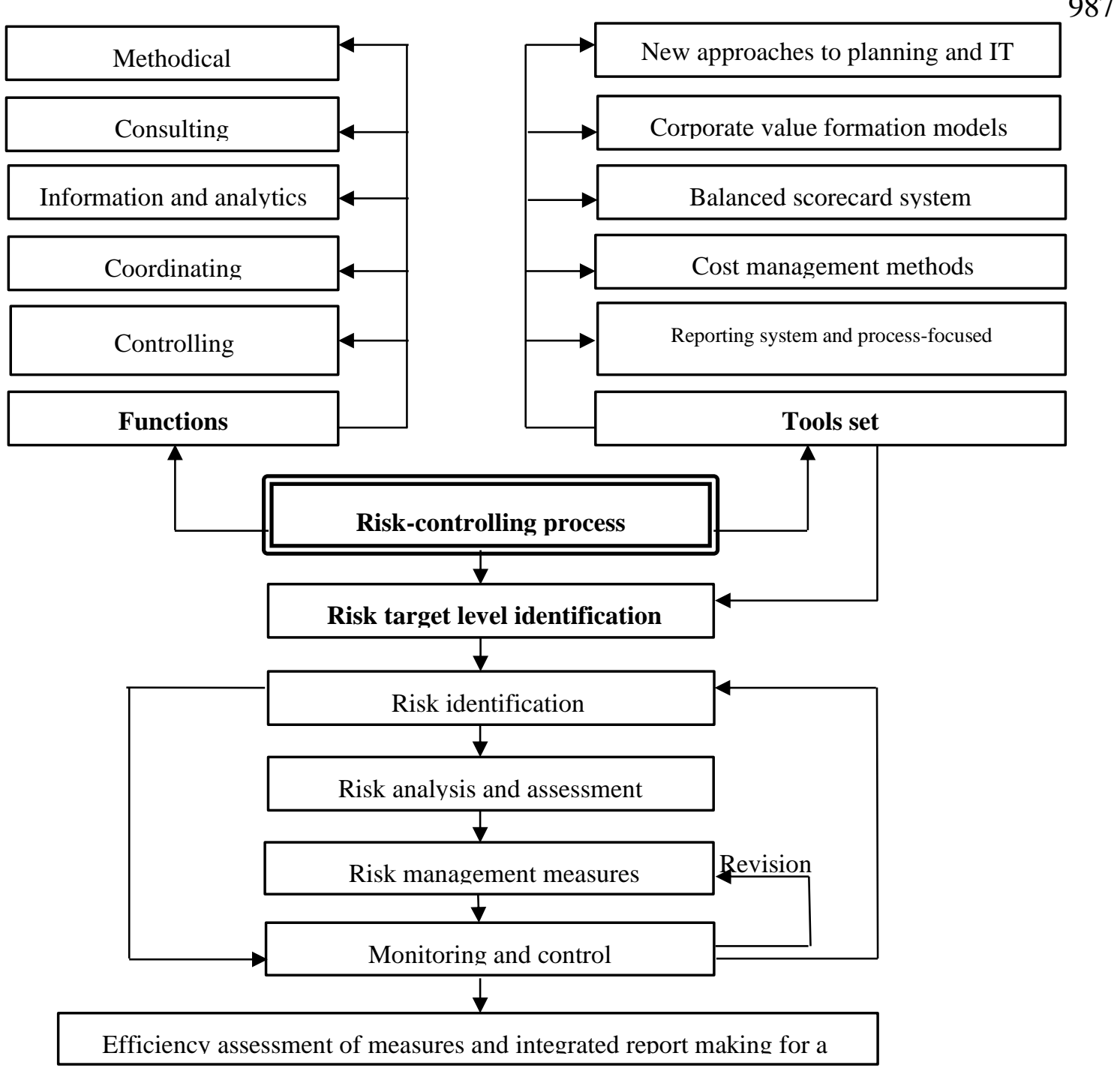

Figure 4. Risk-controlling system functioning at the company

A balanced scorecard (BSC) system is one of the control tools that allows you to manage the company strategic goals and control the efficiency of the company business processes and activities as a whole. The combination of BSC and risk control creates a synergy effect: on the one hand, the strategic objectives reflected in the projections of a balanced scorecard system that allows a systematic approach to risk identification, and, on the other hand, - a detailed risk analysis can identify potential opportunities for the business. Thus, an effective symbiosis of a balanced scorecard system with risk control not only improves the quality of strategic planning but also improves the company risk management process (Portnova and Portnova, 2019). 
Four traditional BSC indicator blocks form the fields of risk search and classification, providing the basis for the risk management to comply with risk identification tasks. The

formation of an enterprise riskcontrolling system of indicators is performed in stages. The indicators are
988 classified from four prospects: finance; client; business processes; development and growth. The factors for achieving the objectives and their quantitative characteristics are determined on the basis of this classification. A fragment of the classification of indicators is shown in Table 1.

Table 1. Business performance indicator classification fragment

\begin{tabular}{|c|c|c|c|}
\hline No. & $\begin{array}{c}\text { Objectives relative to } \\
\text { prospects }\end{array}$ & Objective achievement factors & Indicators \\
\hline \multicolumn{4}{|c|}{ Finance } \\
\hline $\mathrm{F} 1$ & $\begin{array}{l}\text { Company value loss risk } \\
\text { reduction }\end{array}$ & $\begin{array}{l}\text { Company value increase. Increased } \\
\text { return on capital invested. } \\
\text { Optimization of capital costs. }\end{array}$ & $\begin{array}{l}\text { EVA. EVA gain rate. IC } \\
\text { profitability. WACC. Yield spread. } \\
\text { Yield spread growth rate. }\end{array}$ \\
\hline \multicolumn{4}{|c|}{ Clients } \\
\hline $\mathrm{R} 1$ & $\begin{array}{l}\text { Expand the marke } \\
\text { position. }\end{array}$ & Increasing market share. & $\begin{array}{l}\text { Market share growth rate. Various } \\
\text { products growth rate. Market } \\
\text { saturation with such products. }\end{array}$ \\
\hline \multicolumn{4}{|c|}{ Business processes } \\
\hline $\mathrm{P} 1$ & Improve products quality. & $\begin{array}{l}\text { Analysis of causes of deviations in } \\
\text { product quality indicators. Quality } \\
\text { assurance costs. }\end{array}$ & $\begin{array}{l}\text { Reduced loss from defects. Number } \\
\text { of quality claims. }\end{array}$ \\
\hline \multicolumn{4}{|c|}{ Development and growth } \\
\hline K1 & 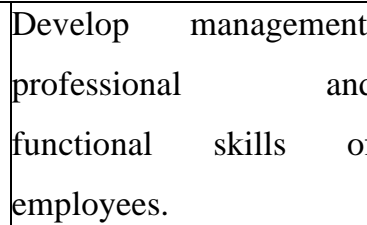 & $\begin{array}{l}\text { Attestation. Advanced training. } \\
\text { Increase in the share of qualified } \\
\text { employees. }\end{array}$ & $\begin{array}{l}\text { Growth rate of staff share with } \\
\text { professional education. Advance } \\
\text { training rate. }\end{array}$ \\
\hline
\end{tabular}

The reliance of key indicators on the company chosen risk management strategy is determined. Key indicators are highlighted for each area in the selected strategy. Cause-and-effect relationships are plotted between targets: the choice of a key indicator is justified; standard values of indicators are set; the selected indicators are checked for reachability; a chain of cause-and-effect 
goals is plotted; the degree of reachability of the objectives based on the cause-effect chain is revealed. Strategic maps of indicators linking the goals of one group to another are plotted. In generalizing, the following conclusions can be made. Building an effective financial risk control system is individual for each company and requires a thorough analysis of all the company processes. Effective operation of such a system requires skilled personnel, process transparency, and control over them, and advanced company planning (Portnova, 2019a; Portnova, 2019b).

\section{Conclusion}

Despite the existing methodological challenges of risk management and financial problems in modern Ukrainian companies, the need to develop and use a risk-controlled early warning system of potential risk objects for risk management and leadership is that risks are more appropriate and profitable to be identified, prevented or avoided in advance, rather than with the help of management impact. Building an effective risk control system will also make it possible not only to effectively minimize risks but also to use risks in the future to obtain additional profit. It may involve employees of various ranks and from different departments of the company. At the same time, it must be borne in mind that the establishment and functioning of independent risk management services are linked to the use of substantial labor and financial resources. Therefore, a separate risk control unit should only be created in large companies. It is advisable to introduce an authorized risk manager with small analytical support staff in medium and small organizations. Direct risk management functions can be transferred to the financial service departments, and risk-controlling functions can be successfully performed by analysts of planning and economic departments, management accounting services and internal audit of enterprises. Management of sustainable development of enterprises of any formation requires the organization of risk management processes. The relevance of risk management is not in doubt, but the introduction of risk management methods is problematic, if not coordinated processes of information base formation, analysis, planning and control of risks. At the enterprise, this function is provided by the risk- 
controlling system. The article analyzes the main problems of risk management in Ukrainian enterprises, methodological approaches to the formation of the riskcontrolling system in the enterprise, formulated recommendations for its implementation.

\section{References}

Allalyev RM. (2019). Religious origins of the rule of law conception in the United States. Amazonia Investiga, 7(14), 212-217.

Bedrinets MD, Denega TM. (2018). Controlling in the system of financial anti-crisis management of the enterprise. Collection of Scientific Papers of the University of DFS of Ukraine, 2(53), 1528.

Bedrinets MD, Surzhenko AV. (2016). Financial management in small business. Kyiv: Center for Educational Literature, $352 \mathrm{p}$.

Blank IA. (2004). Financial strategy of the enterprise. Moscow: Akademiya, $720 \mathrm{p}$.
Blank IA. (2015). Management of financial risks. Moscow: Nika-Center, $390 \mathrm{p}$.

Bliznets IA, Kartskhiya AA, Smirnov MG. (2018). Technology transfer in digital era: legal environment. Tarih Kültür ve Sanat Araştırmaları Dergisi Journal of History Culture and Art Research, 7(1), 354-363.

Cherkasov VV. (1999). Problems of risk in management. Moscow: Refl-book; Kyiv: Vakler, 288 p.

Folmut Kh. (2007). Controlling Tools. Moscow: Avesta, $257 \mathrm{p}$.

Galiyeva GM. (2009). The economic nature and the definition of risk. Voprosy Ekonomicheskikh Nauk, 6, 8-9.

Gordadze G, Kerimov V, Giruts M, Poshibaeva A, Koshelev V. (2018). Genesis of the asphaltite of the Ivanovskoe field in the Orenburg region, Russia. Fuel, 216, 835-842.

Karmansky AM, Falko SG. (2006). Controlling. Moscow: Mysl, 300 p. 
Keil VM. (2008). Place and role of risks in the modern economy. Spravochnik Ekonomista, 9, 33-41.

Kerimov V, Rachinsky M, Mustaev R, Serikova U. (2018a). Geothermal conditions of hydrocarbon formation in the South Caspian basin. Iranian Journal of Earth Sciences, 10(1), 78-89.

Kerimov VYu, Gordadze GN, Lapidus AL, Giruts MV, Mustaev RN, Movsumzade EM, Zhagfarov FG, Zakharchenko MV. (2018b). Physicochemical properties and genesis of the asphaltites of Orenburg oblast. Solid Fuel Chemistry, 52(2), 128-137.

Kerimov VYu, Lapidus AL, Yandarbiev NSh, Movsumzade EM, Mustaev RN. (2017). Physicochemical properties of shale strata in the Maikop series of Ciscaucasia. Solid Fuel Chemistry, 51(2), 122-130.

Kerimov VYu, Mustaev RN, Osipov AV. (2018c). Peculiarities of hydrocarbon generation at great depths in the crust. Doklady Earth Sciences, 483(1), 1413-1417.
Kim YuG. (2005). Financial risks in the system of financial and economic security of an enterprise. Finansy Ukrainy, 6, 13.

Klapkiv MS. (2002). Financial risks insurance. Ternopil: Ekonomichna dumka, 570 p.

Kudabaeva KhI, Yermukhanova LS, Koshmaganbetova GK, Bazargaliev YSh, Baspakova AM, Kaldybaev KK, Kaldybaeva AT. (2015). Estimation of thyroid gland volume by means of ultrasonography among school children in Aktobe area, Kazakhstan. Research Journal of Pharmaceutical, Biological and Chemical Sciences, 6(2), 87-93.

Kudabayeva KhI, Batyrova GA, Bazargaliyev YSh, Baspakova AM, Sakhanova SK. (2018). Hair trace element composition in 6- to 12-year-old children with goiter in West Kazakhstan, a province of the Republic of Kazakhstan. Journal of Elementology, 23(2), 647-657.

Kuznetsov NB, Kerimov VYu, Osipov AV, Bondarev AV, Monakova AS. (2018). Geodynamics of the Ural foredeep and geomechanical modeling 
of the origin of hydrocarbon accumulations. Geotectonics, 52(3), 297-311.

Lapidus AL, Kerimov VYu, Mustaev RN, Movsumzade EM, Salikhova IM, Zhagfarov FG. (2018a). Natural bitumens: physicochemical properties and production technologies. Solid Fuel Chemistry, 52(6), 344-355.

Lapidus AL, Kerimov VYu, Tret'yakov VF, Talyshinskii RM, Ilolov AM, Movsumzade EM. (2018b). Extraction of asphaltite with toluene. Solid Fuel Chemistry, 52(4), 256-259.

Nait F. (2003). Risk, uncertainty and profit. Moscow: Delo, 360 p.

Pickford J. (2004). Risk Management. Moscow: Vershina, 362 p.

Podolchak NYu. (2003). Classification of risks and their mitigation methods. Bulletin of Lviv National University "Lvivska politekhnika", 457, 23-32.

Portnova I, Portnova T. (2019). Stylistic features of European architecture of XX - beginning of XXI century in the light of current trends of the time. Journal of
Mathematics and Computer Science, 1, 51-60.

Portnova T. (2019a). Information technologies in art monuments educational management and the new cultural environment for art historian. TEM Journal, 8(1), 189-194.

Portnova TV. (2019b). Composite image organization of the dramaturgy of dance based paintings. Amazonia Investiga, 8(20), 415-421.

Reta M, Druhova E, Lisnichuk O. (2018). Methods for diagnosing the effectiveness of the enterprise financial strategy in the strategy controlling system. Baltic Journal of Economic Studies, 4(3), 235-243.

Taran AV. (2004). Modern issues of risk perspectives in the financial sphere of enterprises: theoretical generalizations and applied analysis. Kharkiv: Konstanta, 108 p.

Vaganova AS. (2010). Scientific and methodological aspects of riskcontrolling in industrial enterprises. Nizhny Novgorod: NNSTU, 245 p. 
Vitlinsky VV. (2003). Conceptual bases

of riskology in financial activity. Finansy

Ukrainy, 3, 4 